\title{
Subdivisions of the adult zebrafish pallium based on
}

\section{molecular marker analysis [version 1; peer review: 2}

\section{approved, 1 approved with reservations]}

\author{
Julia Ganz1,2, Volker Kroehne1, Dorian Freudenreich1, Anja Machate1, \\ Michaela Geffarth1', Ingo Braasch², Jan Kaslin1,3, Michael Brand1 \\ 1Biotechnology Center, and DFG-Research Center for Regenerative Therapies Dresden, Technische Universität Dresden, Dresden,
01307, Germany
2Institute of Neuroscience, University of Oregon, Eugene, OR 97403, USA
${ }^{3}$ Present address: Faculty of Medicine, Nursing Health Sciences Monash University, Clayton, Victoria, 3800, Australia
}

V1 First published: 17 Dec 2014, 3:308

https://doi.org/10.12688/f1000research.5595.1

Latest published: 04 Nov 2015, 3:308

https://doi.org/10.12688/f1000research.5595.2

\section{Abstract}

Background: The telencephalon shows a remarkable structural diversity among vertebrates. In particular, the everted telencephalon of ray-finned fishes has a markedly different morphology compared to the evaginated telencephalon of all other vertebrates. This difference in development has hampered the comparison between different areas of the pallium of ray-finned fishes and the pallial nuclei of all other vertebrates. Various models of homology between pallial subdivisions in ray-finned fishes and the pallial nuclei in tetrapods have been proposed based on connectional, neurochemical, gene expression and functional data. However, no consensus has been reached so far. In recent years, the analysis of conserved developmental marker genes has assisted the identification of homologies for different parts of the telencephalon among several tetrapod species.

Results: We have investigated the gene expression pattern of conserved marker genes in the adult zebrafish (Danio rerio) pallium to identify pallial subdivisions and their homology to pallial nuclei in tetrapods. Combinatorial expression analysis of asc/1a, eomesa, emx1, emx2, emx3, and Prox1 identifies four main divisions in the adult zebrafish pallium. Within these subdivisions, we propose that $\mathrm{Dm}$ is homologous to the pallial amygdala in tetrapods and that the dorsal subdivision of DI is homologous to part of the hippocampal formation in mouse. We have complemented this analysis be examining the gene expression of emx1, emx2 and emx3 in the zebrafish larval brain. Conclusions: Based on our gene expression data, we propose a new model of subdivisions in the adult zebrafish pallium and their putative homologies to pallial nuclei in tetrapods. Pallial nuclei control sensory, motor, and cognitive functions, like memory, learning and emotion.
Open Peer Review

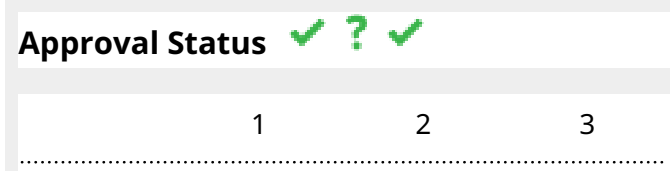

version 2

(revision)

04 Nov 2015

version 1

17 Dec 2014
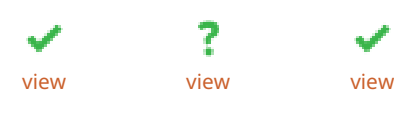

1. Monica Folgueira, University of A Coruña, A Coruña, Spain

2. Perrti Panula, University of Helsinki, Helsinki, Finland

3. Stephen W. Wilson, University College London, London, UK

Any reports and responses or comments on the article can be found at the end of the article. 
The identification of pallial subdivisions in the adult zebrafish and their homologies to pallial nuclei in tetrapods will contribute to the use of the zebrafish system as a model for neurobiological research and human neurodegenerative diseases.

\section{Keywords}

telencephalon, teleost, Actinopterygii , amygdala , hippocampus , neuroanatomy, vertebrate brain, homology, evolution , neurogenesis

Corresponding authors: Julia Ganz (ganz@uoneuro.uoregon.edu), Michael Brand (michael.brand@biotec.tu-dresden.de)

Competing interests: No competing interests were disclosed.

Grant information: This work was supported by grants to MB from the Deutsche Forschungsgemeinschaft (SFB 655 A3), European Union (ZF-Health) and the Center for Regenerative Therapies Dresden (CRTD).

The funders had no role in study design, data collection and analysis, decision to publish, or preparation of the manuscript.

Copyright: @ 2014 Ganz J et al. This is an open access article distributed under the terms of the Creative Commons Attribution License, which permits unrestricted use, distribution, and reproduction in any medium, provided the original work is properly cited. Data associated with the article are available under the terms of the Creative Commons Zero "No rights reserved" data waiver (CCO 1.0 Public domain dedication).

How to cite this article: Ganz J, Kroehne V, Freudenreich D et al. Subdivisions of the adult zebrafish pallium based on molecular marker analysis [version 1; peer review: 2 approved, 1 approved with reservations] F1000Research 2014, 3:308

https://doi.org/10.12688/f1000research.5595.1

First published: 17 Dec 2014, 3:308 https://doi.org/10.12688/f1000research.5595.1 


\section{Background}

The functions of the different parts of the telencephalon encompass control of sensory and motor, autonomic and endocrine functions, as well as cognitive tasks like memory, learning and emotion. The structures in the telencephalon can be assigned either to its dorsal part, the pallium, or its ventral part, the subpallium ${ }^{1-3}$. The telencephalon of most vertebrates forms by an evagination of the neural tube, where the central lumen of the neural tube expands to form the two paired telencephalic vesicles ${ }^{1,3,4}$. However, in ray-finned fishes the rostral neural tube is thought to bend outward resulting in two telencephalic hemispheres separated by an unpaired ventricle and covered by a thin roof plate, thus referred to as "everted" ${ }^{1,3,4}$. In the rayfin teleost zebrafish, it has been shown that the morphogenetic movement that creates this different layout of the telencephalon does not result from a simple lateral outward bending of the telencephalic walls ${ }^{5}$. Instead, telencephalon morphogenesis comprises first the generation of a ventricular outfolding between telencephalon and diencephalon, followed by an enlargement of the pallial territory rostrally ${ }^{5}$. The different development of the telencephalon results in an unpaired ventricle and a different arrangement of the parts in the pallium compared to all other vertebrates ${ }^{1,4,6}$. Hence, due to its everted nature, a comparison between the parts of the pallium of rayfin fishes and all other vertebrates has been difficult. The correct determination of homologous pallial areas between teleosts and tetrapods is critical for the usage of teleost fish as neurobiological models as well as models for human neurological diseases. In recent years, a variety of different studies have demonstrated that using the expression pattern of conserved developmental regulatory genes as landmarks is a useful approach to identify homologous subdivisions of brain regions between divergent vertebrate species. The advantage of using the expression of conserved developmental genes lies in the uncoupling of anatomical and developmental differences of the brain part of interest between divergent species. This approach has been especially valuable for the telencephalon with its great variability in morphology between vertebrate species and has led to the clarification of the homology within subdivisions of the telencephalon between different vertebrate species, such as the domestic mouse, the chicken and the African clawed frog (e.g. ${ }^{7-22}$ ). For example, the gene expression of Tbrl and Eomes (Tbr2) has been successfully used to identify the extent of the pallium in tetrapod embryos ${ }^{9,21,23}$. In addition, absence of Emxl expression and presence of Tbrl expression delineate the ventral pallium in tetrapod embryos ${ }^{9,10,12,13,21}$.

The pallium in teleosts has generally been subdivided in a medial $(\mathrm{Dm})$, dorsal (Dd), central (Dc), lateral (Dl) and posterior (Dp) part ${ }^{4}$. The pallium shows a notable structural variety and different subdivisions of these broad divisions have been described in different teleost species $^{3,24-29}$. The subdivisions of the pallium and their homologies to nuclei in other vertebrate species have not been resolved, but different models based on neurochemical and connectional data have been suggested ${ }^{3,29-38}$. Ablation experiments combined with behavioral experiments suggest that the lateral nucleus of the pallium shows a similarity in function to the hippocampus and the medial nucleus of the pallium to the amygdala of amniotes ${ }^{39-43}$. Based on the expression of nicotine adenine dinucleotide phosphate diphorase (NADPHd) and Parvalbumin, a new model of four subdivisions (Dm, Dc, Dl, and Dp) has been proposed for the adult zebrafish pallium ${ }^{32}$. However, a comprehensive study of pallial subdivisions based on different conserved molecular markers is still missing in the adult zebrafish.

The object of this study was to analyze expression of conserved marker genes to identify subdivisions within the adult zebrafish pallium. Here, we investigated the expression patterns of the molecular marker genes $e m x 1, e m \times 2$, emx 3 to identify a ventral pallial subdivision both in the larval and adult zebrafish pallium. The expression of Prox 1 in a dorsal subdivision of Dl caudally suggests that it is homologous to the dentate gyrus in mouse. Combinatorial expression of asclla, emx1, emx2, emx3, and eomesa shows four main divisions in the pallium, Dm, Dc, Dl, and Dp. The combinatorial expression pattern also suggests a subdivision of $\mathrm{Dl}$ in a dorsal and ventral subdivision (which we have named Dld and Dlv, respectively).

\section{Material and methods}

Fish maintenance

Fish were kept under standard conditions at a 14 hours light/ 10 hours dark cycle as previously described ${ }^{44,45}$. All procedures were in accordance with the live animal handling and research regulations of the local Animal Care and Use Committee, the Regierungspräsidium Dresden (permit AZ 24D-9168.11-1/2008-1 and -4). Wildtype experimental animals (Biotechnology Center Dresden) were adult fish from the gol-b1 line in the AB genetic background ${ }^{46}$. Adult fish were 6-8 months old and had a $24 \mathrm{~mm}-32 \mathrm{~mm}$ body length, zebrafish larvae were $7 \mathrm{dpf}$ old.

\section{Tissue preparation}

Brains (either dissected or within the skull) were fixed at $4^{\circ} \mathrm{C}$ overnight in $2-4 \%$ paraformaldehyde/0.1M phosphate buffer (PB), $\mathrm{pH} 7.5$. They were washed $1 \times 10$ minutes and then up to $1 \mathrm{~h}$ in $0.1 \mathrm{M}$ $\mathrm{PB}$ and subsequently transferred for decalcification and cryoprotection to $20 \%$ sucrose/20\% EDTA in $0.1 \mathrm{M}$ PB, pH7.5. Brains were frozen in $7.5 \%$ gelatine $/ 20 \%$ sucrose and sectioned into $14-16 \mu \mathrm{m}$ cryosections. Sections were stored at $-20^{\circ} \mathrm{C}$.

\section{Orthology analysis between tetrapod and teleost genes}

Compared to tetrapods, teleost fish have undergone an additional whole genome duplication: the teleost genome duplication (TGD) (reviewed $\mathrm{in}^{47}$ ). Thus, there is the possibility of two co-orthologous genes in zebrafish compared to the single tetrapod gene.

We analyzed if there are two co-orthologous genes compared to the tetrapod gene using Ensembl73 gene trees (http://www.ensembl.org) and synteny analysis with the Synteny Database (http://syntenydb. uoregon.edu; ${ }^{48}$ ). This is clearly the case, e.g., for human EOMES with two TGD co-orthologs in zebrafish, eomesa and eomesb (Figure S1A,B).

Two genes are currently termed ascll in zebrafish. Zebrafish asclla is clearly orthologous by phylogeny and conserved synteny to Ascll in lobefins (tetrapods and coelacanth). Zebrafish ascllb not only has a separate ortholog in coelacanth but also shows conserved synteny to tetrapod Ascl2, suggesting that $a s c l 1 b$ is in fact the missing teleost ascl2 gene. 
There are two proxl genes described in zebrafish, yet while proxla is clearly orthologous to tetrapod Proxl, teleost proxlb shows no conserved synteny to teleost proxla or tetrapod Proxl. This suggests that teleost prox $1 b$ represent a more distant prox paralog and is not a TGD paralog of proxla. The phylogeny of the emx genes in zebrafish has previously been determined $\mathrm{in}^{49}$.

\section{RNA in situ hybridization}

RNA in situ hybridization on sections and on whole-mount brains and RNA probe generation was essentially performed as previously described ${ }^{7,50}$. Briefly, after defrosting at room temperature (RT), sections were rehydrated for 15 minutes in PBS with $0.3 \%$ TritonX (PBSTx) and incubated with the probe overnight at 62 $65^{\circ} \mathrm{C}$. Information on the antisense in situ riboprobes can be found in $^{7}$ for asclla (NM_131219), emx1 (NM_198144), emx2 (NM_ 131280), emx3 (NM_131279), eomesa (NM_131679). The in situ probe eomesb (NM_001083575) was cloned from zebrafish embryonic cDNA with the following primers (eomes $b$-F, TTTCCAAAACGAAAAGCGTA, eomes $b$-R, GAGCCAGAACTGGATCCTTCT). The eomes $b$ probe was tested on $3 \mathrm{dpf}$ embryos and showed specific staining only in the midbrain at $3 \mathrm{dpf}$ (Figure S2, Dataset 1). The sections were washed at $60-65^{\circ} \mathrm{C}$ in washing solution $(1 \times \mathrm{SSC}$, $50 \%$ deionized formamide) for $1 \times 15$ minutes and $2 \times 30$ minutes followed by $2 \times 30$ minutes MAB with $0.1 \%$ Tween-20 (MABT) washes. Sections were incubated for $1 \mathrm{~h}$ at RT in $2 \%$ DIG-blocking reagent (Roche) and incubated with anti-DIG antibody (Roche Diagnostics, sheep, polyclonal, Fab fragments conjugated to alkaline phosphatase, \#11093274910) diluted 1:4000 in 2\% DIG-blocking reagent overnight at $4^{\circ} \mathrm{C}$. Subsequently, sections were washed $4 \times 20$ minutes in MABT, equilibrated with staining buffer and stained with the substrate NBT/BCIP. The staining was controlled using a stereomicroscope. Finally, sections were washed $2 \times 5$ minutes in PBS, postfixed with 4\% PFA for 20-30 minutes, washed again $2 \times 10$ minutes in PBS and mounted with $70 \%$ glycerol in PBS. All washing steps were performed on a shaker, all incubation steps in a humid chamber. To test for nonspecific binding of the antibodies that detect digoxigenin, which are not endogenous to vertebrate tissue, we performed control experiments in which the labeled RNA was omitted from the hybridization mix. No signal was detected in the absence of the riboprobe, demonstrating that the antibody reacts specifically with the synthetic RNA (Dataset 2).

\section{Immunohistochemistry}

Immunohistochemistry on cryosections was performed as previously described ${ }^{51}$. Briefly, to retrieve the antigens of Prox1, sections were pre-incubated in $50 \mathrm{mM}$ Tris-buffer $\left(\mathrm{pH} \mathrm{8.0)}\right.$ ) at $99^{\circ} \mathrm{C}$ for 5 minutes, cooled down to RT over 15 minutes and washed for 5 minutes in PBS and twice for 10 minutes in PBSTx. The sections were then incubated in primary and secondary antibodies in PBSTx. The primary antibody Prox1 (AB5475, 1:2000, Millipore) was incubated overnight at $4{ }^{\circ} \mathrm{C}$ and secondary antibodies for $1 \mathrm{~h}$ at room temperature. The slides were washed in PBSTx and mounted. The secondary antibody (dilution 1:750) was Alexa 488-Fluor conjugated (A-11034, Invitrogen, Karlsruhe).

\section{Image acquisition and processing}

Confocal images were acquired with Leica TCS-SP5 confocal microscope. Brightfield images were acquired with Zeiss Axio
Imager Z1. The images were processed using ImageJ v. 1.4.3.67 and Adobe Photoshop CS2. Composites were assembled using Adobe Photoshop CS2 and Adobe Illustrator CS2.

\section{Nomenclature}

We primarily followed the nomenclature proposed in $^{32}$ with modifications based on our combinatorial expression pattern analysis, which suggest a subdivision of $\mathrm{Dl}$ in a dorsal and ventral subdivision (which we have named Dld and Dlv, respectively). In the figures we employ a two-color code to separate subdivisions that can be made based on the current marker (red dashed line) from those that we make based on other markers (white dashed line). The black dashed line indicates the boundary between $\mathrm{D}$ and $\mathrm{V}$. The distinction of ventricular zone versus neuronal layer was based on cellular morphology. The ventricular zone is the region where cells are directly facing the ventricle. The neuronal layer is characterized by cells with a round shape.

\section{Results}

Expression of eomesa in the adult zebrafish pallium In tetrapod embryos, Eomes (Tbr2) expression is found in the ventricular zone and mantle layer in all parts of the pallium at embryonic stages ${ }^{9,21,23}$. In the zebrafish embryo, eomesa expression is present throughout the dorsal telencephalon ${ }^{52,53}$. Its TGD paralog, eomes $b$ is not present in the embryonic or adult telencephalon (Figure S2, Dataset 1) and thus was not further taken into account. In the adult zebrafish, eomesa positive cells are scattered in a salt-and-pepper pattern along the ventricular zone of Dm along the rostro-caudal axis (Figure 1A-D, arrowheads). Further, eomesa expression is present in the ventricular zone and neuronal layer of Dc, Dlv and Dld in the rostral telencephalon and at mid-telencephalic levels and in the ventricular zone and neuronal layer of Dld and Dp at the anterior commissure (Cant; Figure 1A-C). Caudal to Cant, eomesa is expressed in the ventricular zone and neuronal layer of Dp, sporadically in Dld and in bed nucleus of the stria medullaris (BNSM, Figure 1D). In summary, eomesa is differentially expressed in the pallium along the rostro-caudal axis (Figure 1E-H, Dataset 3; Table 1). The most abundant parenchymal eomesa expression is detected in parts of the central and lateral dorsal telencephalic nuclei.

\section{Expression of emx1, emx2 and emx3 in the adult zebrafish pallium}

In tetrapod embryos, the ventral pallial subdivision is characterized by absence of Emxl and presence of $\operatorname{Tbr} 1^{9,10,12,13,21}$. In embryonic and adult zebrafish, $t b r l$ is expressed throughout the pallium ${ }^{7,53,54}$. Thus, we investigated the expression of emxl, emx 2 and $e m \times 3$ to identify a ventral pallial subdivision in the zebrafish pallium. In zebrafish, the three emx genes are expressed at 1 day post fertilization (dpf) in the embryo throughout the dorsal telencephalon ${ }^{49,55,56}$. In 7 day-old larva, the expression of $e m x 1$ and $e m \times 2$ is restricted to a small caudo-lateral area in the dorsal telencephalon (Figure $\mathrm{S} 3 \mathrm{~A}, \mathrm{~B}, \mathrm{D}$, Dataset 4). The expression of $e m \times 3$ is found throughout the dorsal telencephalon (Figure S3C,E, Dataset 4). In the adult zebrafish pallium, emxl and $e m \times 2$ are expressed in a very restricted fashion. The expression of emxl only starts in the midtelencephalon shortly rostral to Cant, where it is restricted to the ventricular zone and neuronal layer of $\mathrm{Dp}$. This expression pattern continues to Cant (Figure 2A). Furthermore, emxl expression is 


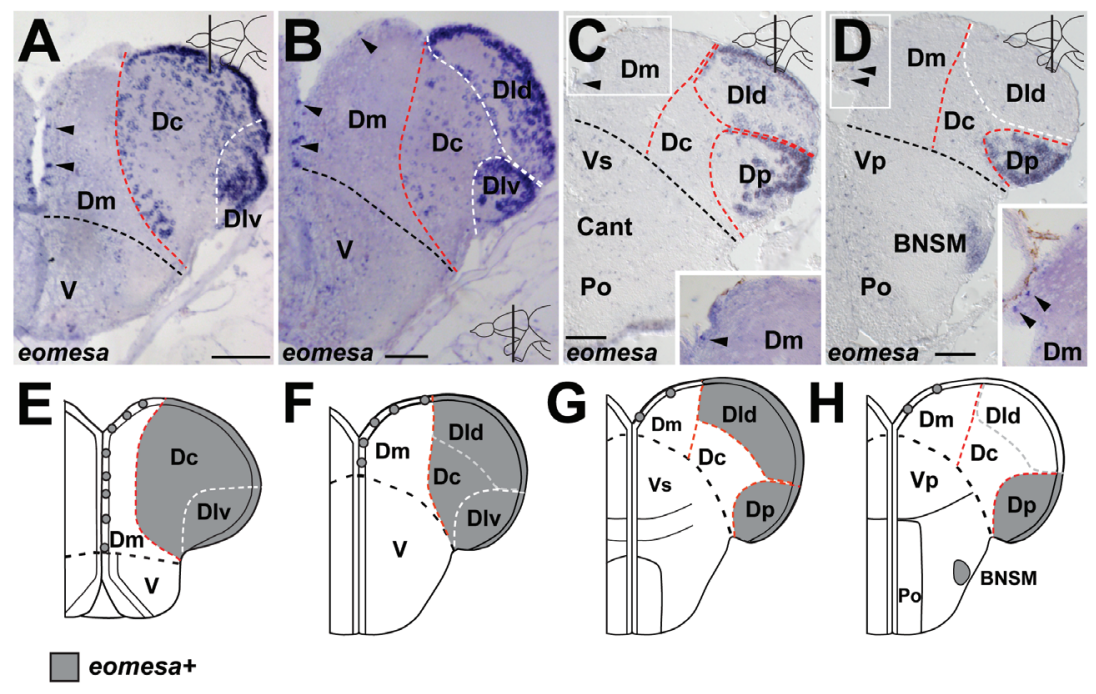

Figure 1. Expression of eomesa in the pallium. A. In the rostral telencephalic, eomesa expression is found in the ventricular zone (vz) of Dm (arrowheads) and in the vz and neuronal layer (nl) of Dc and Dlv. B. At mid-telencephalic levels, eomesa expression is present in the vz of Dm (arrowheads), in the $\mathrm{nl}$ of Dc and in the $\mathrm{vz}$ and $\mathrm{nl}$ of Dld and Dlv. C. At the anterior commissure (Cant), eomesa expression is present in the vz of Dm (arrowhead) and in the vz and $\mathrm{nl}$ of Dld and Dp. Inset shows close-up of vz of Dm $\mathbf{D}$. Caudal to Cant, eomesa expression is present in the vz of Dm (arrowhead), in the vz and $\mathrm{nl}$ of Dp and in BNSM. Inset shows close-up of vz of Dm E.-H. Summary of the expression pattern of eomesa at rostral (E.), mid-telencephalic (F.), commissural (G.) and postcommissural levels (H.). A. - D. Brightfield images of cross-sections at the levels indicated through the telencephalon. Red dashed line indicates subdivisions based on the current marker. White dashed line indicates subdivisions based on other markers. The black dashed line indicates the boundary between D and V. Scale bars $=50 \mu \mathrm{m}$ in $\mathbf{A}-\mathbf{D}$.

\section{Table 1. Summary of gene expression pattern in the adult zebrafish pallium.}

\begin{tabular}{|c|c|c|c|c|c|c|}
\hline & ascl1a & eomesa & $e m \times 1$ & $e m \times 2$ & $e m \times 3$ & Prox 1 \\
\hline Dm & $3 v z^{a}$ & $3 v z^{a}$ & 0 & 0 & $3 \mathrm{vz} \mathrm{nl}$ & 0 \\
\hline Dc & 0 & 3 vz nl/ $0^{b}$ & 0 & $0 / 3 \mathrm{nl}^{\mathrm{c}}$ & $1-2 \mathrm{nl}^{\mathrm{d}}$ & 0 \\
\hline Dld & 0 & $3 \mathrm{vz} \mathrm{nl^{ \textrm {e } }}$ & 0 & 0 & 0 & $0 / 3 \mathrm{nl}^{\mathrm{f}}$ \\
\hline Dlv & $2 v z^{a}$ & $3 \mathrm{vz} \mathrm{nl}$ & 0 & 0 & $2 \mathrm{vz} \mathrm{nl}{ }^{9}$ & 0 \\
\hline Dp & $2 v z^{a}$ & $3 \mathrm{vz} \mathrm{nl}$ & $3 \mathrm{vz} \mathrm{nl}$ & 0 & $2 \mathrm{vz} n \mathrm{l}$ & 0 \\
\hline EN & 0 & 0 & $3 \mathrm{nl}$ & 0 & 0 & 0 \\
\hline BNSM & 0 & $3 \mathrm{nl}$ & 0 & 0 & 0 & 0 \\
\hline
\end{tabular}

0 expression not detected, 1 weak expression, 2 moderate expression, 3 strong expression, vz ventricular zone, $\mathrm{nl}$ neuronal layer,

${ }^{a}$ scattered cells in the ventricular zone; ${ }^{b}$ no expression from midtelencephalic levels; c part of Dc posterior to Cant; ${ }^{d}$ scattered cells in the neuronal layer; ${ }^{e}$ no expression posterior to Cant; ${ }^{\dagger}$ expression at midtelencephalic level shortly anterior to Cant, shortly caudal to Cant, only scattered Prox $1+$ cells are present; ${ }^{g}$ expression present in the rostralmost telencephalon in the $\mathrm{vz}$, moving caudally expression in $\mathrm{vz}$ and $\mathrm{nl}$.

present in Dp and in EN caudal to Cant (Figure 2B). The expression of emx2 is only found caudal to Cant in an area in Dc lateral to Vp (Figure 2C). Similar to the larvae, emx3 shows the broadest expression of the emx genes. In the rostral telencephalon, the expression of emx3 is found in the ventricular zone and neuronal layer of Dm and weakly in scattered cells in the neuronal layer of
Dc (Figure 2G). Additionally, the expression of emx3 is weakly present rostrally in the ventricular zone of Dlv (Figure 2G, arrowheads). At mid-telencephalic levels, emx3 expression is found in the ventricular zone and neuronal layer of Dm, in scattered cells in Dc and in the ventricular zone and neuronal layer of Dlv (Figure 2H). At Cant, expression of $e m \times 3$ is found in the ventricular zone and neuronal layer of Dm, in scattered cells in Dc and in the ventricular zone and neuronal layer of Dp (Figure 2I). Caudal to Cant, the expression gets weaker in Dm, Dc and Dp (data not shown). In summary, emxl and emx2 show a very restricted expression pattern in the adult zebrafish pallium (Figure 2D-F, Dataset 5; Table 1). Expression of emx3 is present in Dm, Dc and Dlv/Dp (Figure 2J-L, Dataset 5; Table 1).

Expression of Prox1 in the adult zebrafish pallium During mouse development, Proxl expression is found in the amygdala, dentate gyrus and in the neocortex ${ }^{57}$. At adult stages, however, strong Prox 1 expression is restricted to the dentate gyrus of the hippocampus and is commonly used as a specific marker for granule cells of the hippocampus ${ }^{57-60}$. In the adult zebrafish pallium, Prox $1+$ cells only are present in the midtelencephalon shortly rostral to Cant in the neuronal layer of Dld (Figure 3A). This expression pattern continues to the anterior commissure (Figure 3B). Shortly caudal to Cant, only scattered Prox $1+$ cells are present in Dld, more caudally no Prox 1+ cells can be found (data not shown). In summary, Prox 1 staining is present in Dld starting at mid-telencephalic levels until shortly caudal to Cant (Figure 3A-D, Dataset 6; Table 1). 


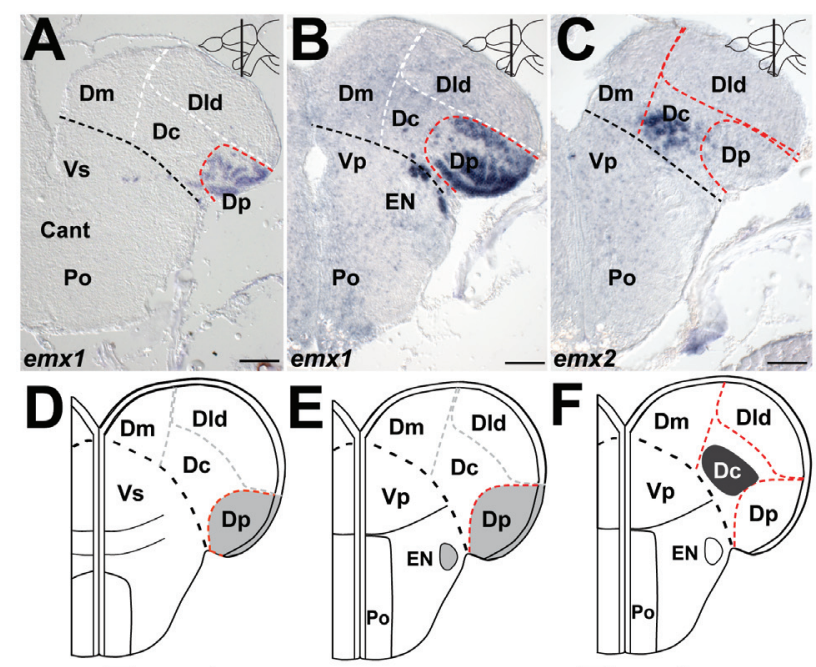

emx1+

emx2+

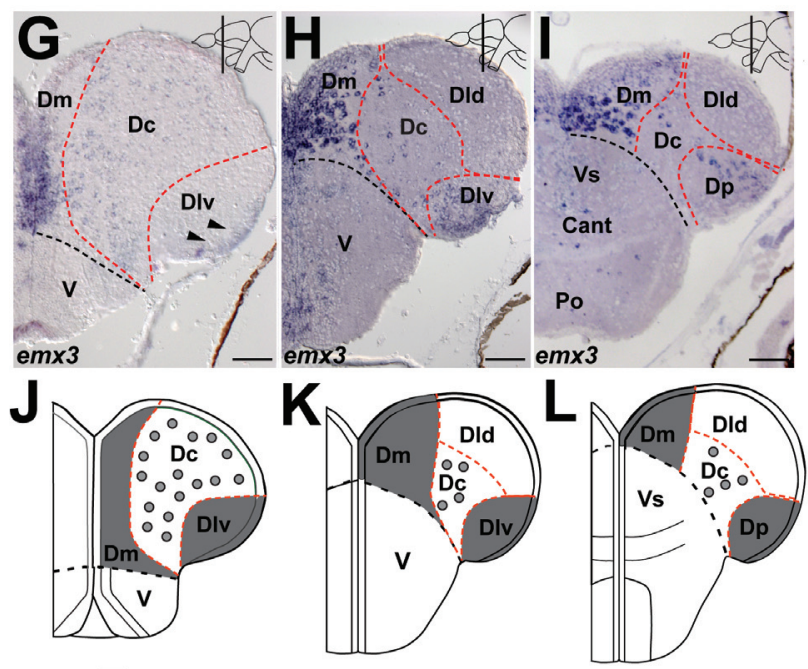

em $\times 3+$

Figure 2. Expression of $\mathbf{e} \mathbf{x} \mathbf{1}, \mathbf{e} \mathbf{e} \times \mathbf{2}$ and $\mathbf{e} \mathbf{m} \times \mathbf{3}$ in the pallium. A. At the anterior commissure (Cant), emx1 expression is found in neuronal layer ( $\mathrm{nl}$ ) and ventricular zone ( $\mathrm{vz}$ ) of Dp. B. Caudal to Cant, emx1 expression is present in the vz and $\mathrm{nl}$ of Dp and in EN. C. Caudal to Cant, emx2 expression is present in part of Dc. D.-F. Summary of the expression pattern of emx1 and emx2 at commissural (D.) and postcommissural levels (E.,F.). G. In the rostral telencephalon, emx3 expression is present in the vz and nl of Dm, weakly in scattered cells of the $\mathrm{nl}$ od Dc and in the vz of Dlv (arrowheads). H. At mid-telencephalic levels, emx3 expression is found in the vz and $\mathrm{nl}$ of Dm, in scattered cells in Dc, and in the vz and nl of DIv. I. At Cant, emx3 expression is present in the vz and nl of Dm, in scattered cells in Dc and in the vz and $\mathrm{nl}$ of Dp. J.-L. Summary of the expression pattern of emx3 at rostral (J.), mid-telencephalic (K.) and commissural levels (L.). A. $-\mathbf{F}$. Brightfield images of cross-sections at the levels indicated through the telencephalon. Red dashed line indicates subdivisions based on the current marker. White dashed line indicates subdivisions based on other markers. The black dashed line indicates the boundary between $\mathrm{D}$ and $\mathrm{V}$. Scale bars $=50 \mu \mathrm{m}$ in $\mathbf{A}-\mathbf{D}$.

Expression of ascl1a in the adult zebrafish pallium

In tetrapod embryos, Ascll is expressed a subpopulation of progenitors in the dorsal telencephalon ${ }^{61,62}$. In the zebrafish embryo, asclla expression is present in the caudomedial ventricular zone of the dorsal telencephalon ${ }^{63}$. In the adult zebrafish pallium, asclla is expressed in scattered cells in the ventricular zone of Dm and in scattered cells in the ventricular zone of Dlv (Figure 4A-D, arrowheads, Figure 4I,J, Dataset 7; Table 1). At Cant and posterior to Cant asclla is present in scattered cells in Dm and Dp (Figure 4E-H, arrowheads, Figure 4K,L, Dataset 7; Table 1).

\section{Gene expression analysis in the adult zebrafish pallium}

47 Data Files

http://dx.doi.org/10.6084/m9.figshare.1266194

\section{Discussion}

Subdivisions of the zebrafish pallium and their homology to other vertebrates

Due to the different development, the pallium of ray-finned fishes has a markedly different morphology compared to all other vertebrates, 


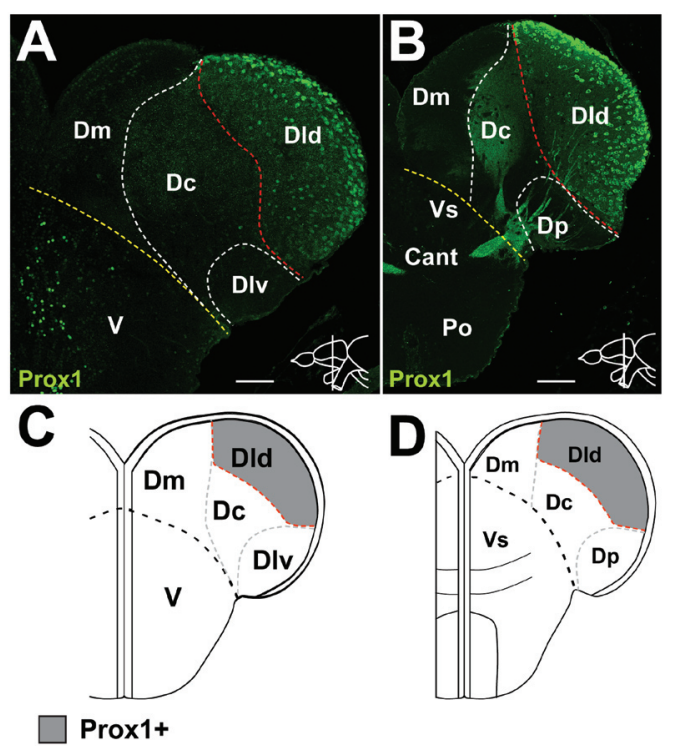

Figure 3. Expression of Prox1 in the pallium. A. At mid-telencephalic levels, Prox1 positive cells are found in the neuronal layer (nl) of Dld shortly before the anterior commissure (Cant). B. At Cant, Prox1 positive cells are found in the nl of Dld. C.-D. Summary of expression pattern of Prox1. A.-B. Confocal images of cross-sections at the levels indicated through the telencephalon. Red dashed line indicates subdivisions based on the current marker. White dashed line indicates subdivisions based on other markers. The yellow dashed line indicates the boundary between D and V. Scale bars $=50 \mu \mathrm{m}$ in A-B.

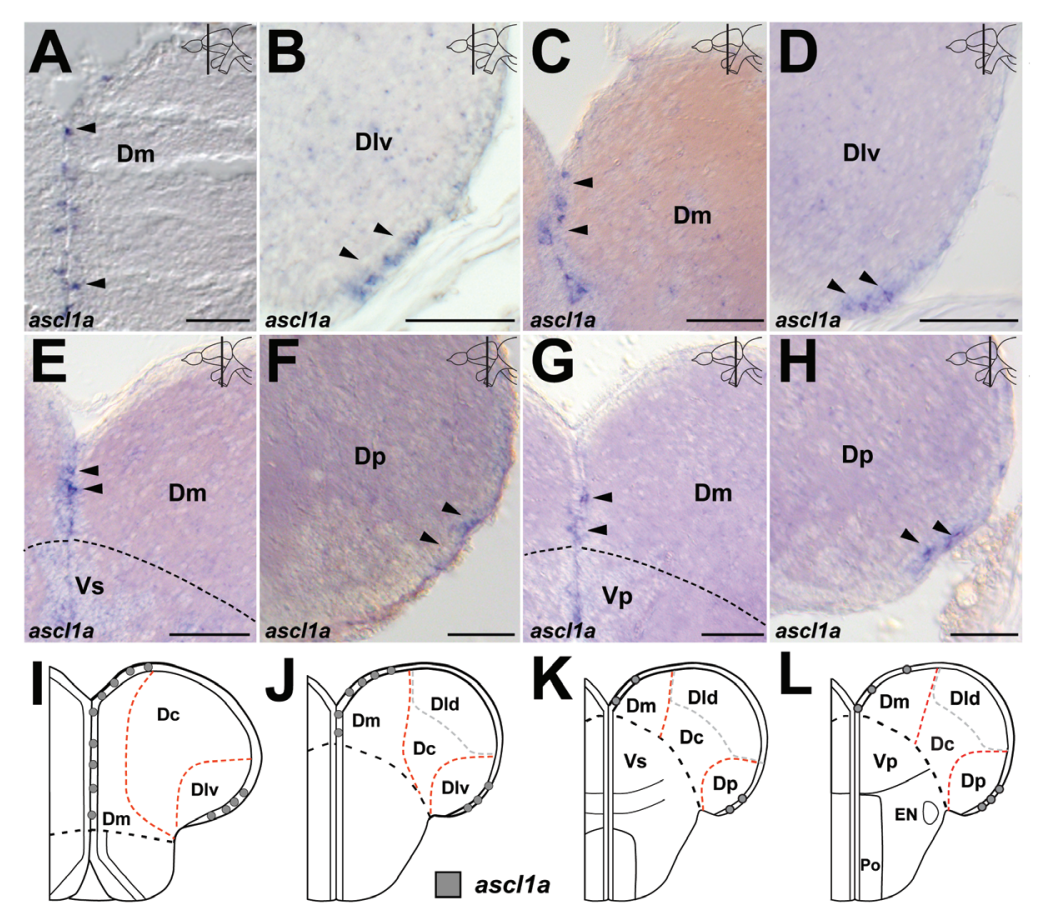

Figure 4. Expression of ascl1a in the pallium. A.-B. In the rostral telencephalon, asc/1a expression is present in scattered cells in the ventricular zone (vz) of Dm (A, arrowheads) and Dlv (B, arrowheads). C.-D. At mid-telencephalic levels, asc/1a expression is present in scattered cells in the vz of Dm (C, arrowheads) and DIv (D, arrowheads). E.-F. At Cant, asc/1a expression is present in scattered cells in the Vz of Dm (E, arrowheads) and Dp ( $\mathbf{F}$, arrowheads). $\mathbf{G}$. - H. Posterior to Cant, asc/1a expression is present in scattered cells in the vz of Dm (G, arrowheads) and Dp (H, arrowheads). I.-L. Summary of the expression pattern of asc/1a rostral (I.), mid-telencephalic (J.), commissural (K.) and postcommissural levels (L.). A.-H. Brightfield images of cross-sections at the levels indicated through the telencephalon. Red dashed line indicates subdivisions based on the current marker. White dashed line indicates subdivisions based on other markers. The black dashed line indicates the boundary between D and V. Scale bars $=50 \mu \mathrm{m}$ in $\mathbf{A}-\mathbf{C}$. 
which makes the comparison between the areas of the pallium of ray-finned fishes to pallial nuclei of other vertebrates particularly challenging. Yet, the correct assignment of homologous pallial areas between teleosts and tetrapods is essential for usage of the teleost fish model in neurobiological research. We have analyzed several conserved molecular marker genes that are found in specific areas of the pallium in the domestic mouse, chicken and the African clawed frog. Based on the expression analysis we identify four main subdivisions of the pallium (Dm, Dl, Dc and Dp) and propose that Dl is subdivided in a dorsal (Dld) and ventral part (Dlv). Based on our data we also suggest putative homologies to pallial nuclei in tetrapods. We suggest that $\mathrm{Dm}$ is homologous to the ventral or ventral/lateral pallium, Dc to the dorsal pallium, Dl to the medial pallium, and suggest that Dp comprises a specialized part of Dl (Figure 5). Additional marker analysis, lineage tracing experiments and functional analyses will be necessary to substantiate the proposed pallial subdivisions and their homology to pallial nuclei in tetrapods. As our study is based solely on comparative gene expression data, we have discussed our results in the framework of gene expression data of other organisms and subsequently compared them to connectional, neurochemical, and functional data in teleosts. For clarity, we discuss our results separately for each pallial subdivision.

\section{Medial part of the area dorsalis telencephali (Dm)}

In the African clawed frog, the chicken, and the domestic mouse, four pallial divisions have been identified in the embryo, the ventral pallium (VP), the lateral pallium (LP), the dorsal pallium (DP) and the medial pallium (MP) ${ }^{9,10,13,21}$. In the African clawed frog, chicken, and domestic mouse, the ventral pallial subdivision is characterized in the embryo by the absence of Emxl expression and presence of the pallial marker $\operatorname{Tbr} 1^{9,10,13,21}$. In embryonic and adult zebrafish, tbrl is expressed throughout the pallium ${ }^{7,53,54}$. In adult ray-finned fishes, Dm has been proposed to be homologous to the ventral pallium (pallial amygdala) based on topological, connectional and functional data ${ }^{29-31,64-66}$. In contrast, Nieuwenhuys (2009) proposed that $\mathrm{Dm}$ is homologous to the lateral pallium based on topology and Yamamoto et al. (2007) suggest that Dm together with Dd and Dld is homologous to the dorsal pallium. Thus, we analyzed the expression of the emx genes in the larval and adult zebrafish to determine if the absence of these markers identifies a ventral pallial subdivision in the zebrafish pallium. In zebrafish, the emx genes show a dynamic expression pattern both in the embryo and the adult. At $1 \mathrm{dpf}$, the three emx genes are expressed at throughout the dorsal telencephalon ${ }^{49,55,56}$. We found that expression of emxl is restricted to a caudolateral expression domain in the zebrafish larvae at $7 \mathrm{dpf}$ and to Dp in the adult (Figure 2D,E, Figure S3). Similarly, emx2 also shows a restricted expression pattern to a caudolateral domain both in the zebrafish larvae at 7dpf and in the adult zebrafish pallium (Figure 2F, Figure S3). The expression of emx3 is present in the entire pallium in the zebrafish embryo and larvae $\left({ }^{49}\right.$, Figure S3C). In the adult, emx3 is present in the rostral telencephalon in Dm, Dc and in the ventricular zone of Dlv (Figure 2J). Moving caudally, emx3 is present in Dm, in scattered cells in Dc and in the ventricular zone and neuronal layer of Dlv and Dp (Figure 2K,L). As it has been previously suggested that zebrafish $e m x 3$ supplies the functions provided by Emx1 and Emx2 in mouse ${ }^{49}$, we took the combined expression pattern of the three $e m x$ genes into account for our analysis. The lack of an area in Dm that is $t b r l$ positive and $e m x$ gene negative suggests that zebrafish might not have a distinct ventral pallial subdivision and that Dm is either homologous to the lateral pallium, or that Dm comprises a combined ventral and lateral pallium (Figure 5A-D). Emxl alone might not be an adequate marker for the ventral pallium in the domestic mouse and chicken, as they have lost the Emx3 gene $^{49}$.

Both the ventral pallium and the lateral pallium contribute together with subpallial derivatives to the amygdaloid complex in tetrapods ${ }^{10,67,68}$. In rodents, the Cannabinoid Receptor (CB1) is expressed in a subset of neurons in the basolateral amygdala ${ }^{69,70}$. In the weakly electric fish Apteronotus leptorhynchus and zebrafish, cbl is expressed in $\mathrm{Dm}^{71-73}$, thus supporting the model that $\mathrm{Dm}$ is homologous to the pallial amygdala. Based on gene expression analysis, we have suggested previously that the supracommissural nucleus of the area ventralis telencephali (Vs) is homologous to the dorsal and ventral part of the central amygdala and the bed nucleus of the stria terminalis (BST) and that the postcommissural nucleus of the area ventralis telencephali $(\mathrm{Vp})$ is homologous to the dorsal part of the central amygdala and the $\mathrm{BST}^{7}$. Thus, it is plausible that Vs and Vp (subpallial amygdala) and Dm (pallial amygdala) form the amygdaloid complex in the adult zebrafish (Figure 5A-E).

\section{Lateral part of the area dorsalis telencephali (DI)}

Based on topological and gene expression data it has been proposed that the entire $\mathrm{Dl}^{4}$ or $\mathrm{Dl}$ excluding Dlv or Dp is homologous to the medial pallium in other vertebrates ${ }^{24,30,32,64}$. In contrast, Wullimann and Mueller (2004) considered only Dlv to be homologous to the medial pallium and Yamamoto et al. (2007) proposed that only the dorsal part of $\mathrm{Dl}$ is homologous to the medial pallium. Functional ablation experiments suggested that $\mathrm{Dl}$ is equivalent to the hippocampus of tetrapods ${ }^{65}$. Our combinatorial expression data suggests that Dl is subdivided in Dld and Dlv rostrally and at Cant and posterior to Cant in Dld and Dp (Figure 5A-D). During mouse development, Proxl expression is found in the amygdala, dentate gyrus and in the neocorte $x^{57}$. At adult stages, however, strong Proxl expression is restricted to the dentate gyrus of the hippocampus and is commonly used as a specific marker for granule cells of the hippocampus ${ }^{57-59}$. In the adult zebrafish, Prox 1 positive cells are exclusively present in the caudal part of Dld. In summary, our data suggests that Dl (excluding Dp, see below) may be homologous to the medial pallium and hippocampus and the caudal part of Dld homologous to the dentate gyrus in the domestic mouse (Figure 5A-E). We will discuss the possible homology of Dp in the subsequent part.

\section{Posterior part of $\mathrm{D}(\mathrm{Dp})$}

It has previously been shown that Dp receives olfactory input and has been on this basis homologized to the lateral pallium in amphibians and all other gnathostomes with evaginated forebrains ${ }^{4}$. Being homologous to the lateral pallium, it should be located next to Dm in the embryo, the presumptive ventral pallium. The discrepancy between the position of Dp in the adult and an expected location next to Dm has led to different models to explain the different position of Dp in the adult pallium: "the partial pallial eversion 

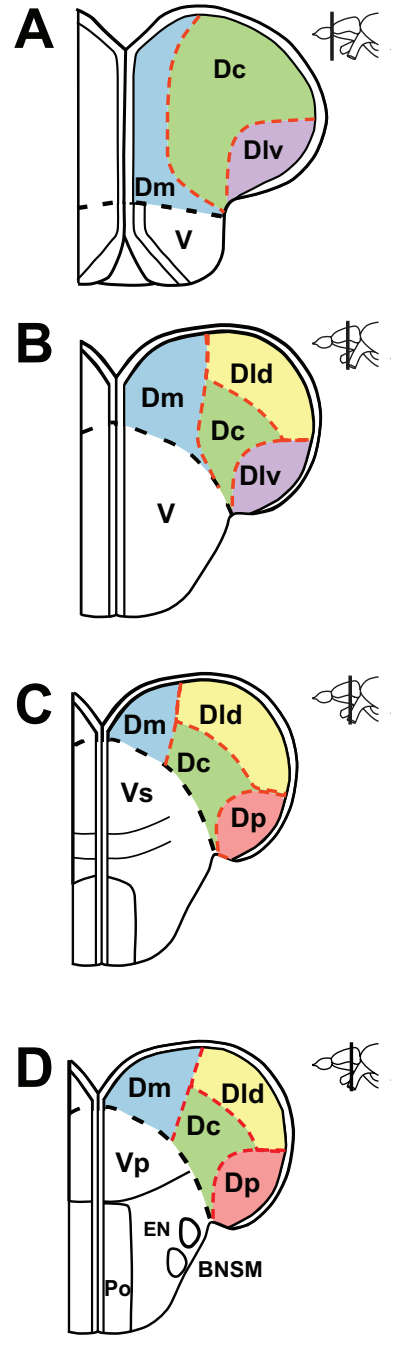

\section{Putative homologous region in the tetrapod pallium}

ventral/lateral pallium or lateral pallium $(\mathrm{Dm})$ - pallial amygdala

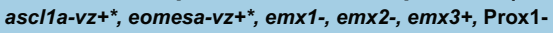

\section{dorsal pallium (Dc) - cortex}

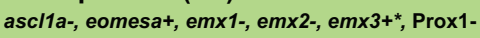

medial pallium (DIv) - hippocampus

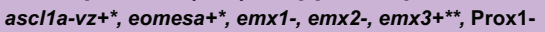

ventral/lateral pallium or lateral pallium $(\mathrm{Dm})$ - pallial amygdala ascl1a-vz+*, eomesa-vz+*, emx1-, emx2-, emx3+, Prox1-

dorsal pallium (Dc) - cortex

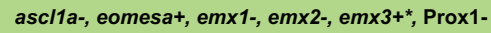

medial pallium (DId) - hippocampus

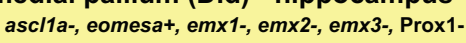

medial pallium (DIv) - hippocampus

ascl1a-vz+, eomesa+, emx1-, emx2-, emx3-vz+/nl+/-, Prox1-

ventral/lateral pallium or lateral pallium (Dm) - pallial amygdala

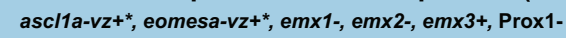

dorsal pallium (Dc) - cortex

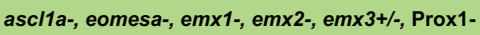

medial pallium (DId) - hippocampus (dentate gyrus)

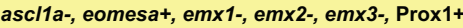

medial pallium (Dp) - (n/a)

ascl1a-vz+, eomesa+, emx1+, emx2-, emx3+, Prox1-

ventral/lateral pallium or lateral pallium (Dm) - pallial amygdala (Dm) ascl1a-vz+*, eomesa-vz+*, emx1-, emx2-, emx3+, Prox1-

dorsal pallium (Dc) - cortex

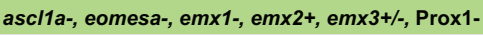

medial pallium (DId) - hippocampus

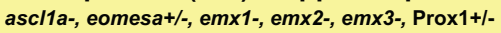

medial pallium (Dp) - (n/a)

ascl1a-vz+, eomesa+, emx1+, emx2-, emx3+, Prox1-

$\mathbf{E}$

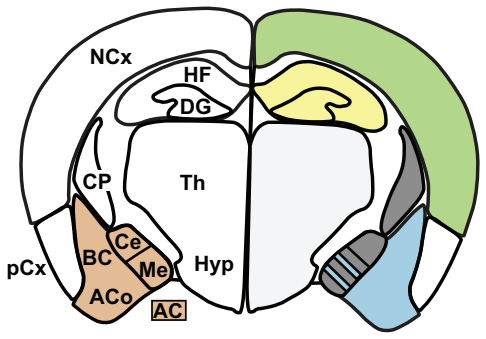

Figure 5. Summary of the gene expression patterns in the adult zebrafish pallium. A.-D. Cross-sections at the levels indicated through the telencephalon. E. Schematic diagram of a cross section through the mouse telencephalon for comparison (modified after ${ }^{14}$ ), note that the amygdaloid complex (AC, brown) is derived both from subpallium (grey) and pallium. Light grey areas (Th/Hyp) are part of the diencephalon. Indicated is also a model of the putative homology of the subdivisions in the adult zebrafish pallium to regions in the tetrapod pallium taking the data presented in this paper into account. Additional marker analysis, lineage tracing experiments and functional analyses are necessary to substantiate the proposed homology to pallial nuclei in tetrapods. ${ }^{*}$ in scattered cells, ${ }^{* *}$ in Dlv in the ventricular zone, moving caudally expression in the neuronal layer and ventricular zone, note that Prox 1 positive cells are present in Dld shortly before the anterior commissure, $\mathrm{n} / \mathrm{a}=$ not applicable. The black dashed line indicates the boundary between $\mathrm{D}$ and $\mathrm{V}$. The red dashed lines indicate the boundaries between different nuclei in $\mathbf{D}$. AC amygdaloid complex, ACo anterior cortical amygdalar area, BC basal amygdalar complex, BNSM bed nucleus of the stria medullaris, Ce central amygdala, CP Caudateputamen, DG dentate gyrus, EN entopeduncular nucleus, HF hippocampal formation, Hyp hypothalamus, Me medial amygdala, NCx neocortex, pCx piriform cortex, Po preoptic region, Th thalamus, $V$ area ventralis telencephali, Vp postcommissural nucleus of the area ventralis telencephali, Vs supracommisural nucleus of the area ventralis telencephali. 
model" by Wullimann and Mueller ${ }^{31,32,52,74}$, the "eversion-rearrangement theory" by Northcutt and Braford ${ }^{33,64,75}$, and the "new eversion model" by Yamamoto and colleagues ${ }^{37}$. In the "partial pallial eversion model" $31,32,52,74$, based on connectional and gene expression data, it has been proposed that the homolog of the lateral pallium does not participate in the eversion. Wullimann and Mueller put forward that neuroblasts generated by the ventricular zone of the uneverted, medially located lateral pallium homolog migrate laterally to give rise to the submeningeally located nucleus $\mathrm{Dp}^{31,74}$. Our gene expression analysis does not support this part of their modified partial eversion model. Based on differential gene expression we can identify Dp, which is not located submeningeally, but has its own ventricular zone even in the adult ${ }^{4,64,76}$. New neurons are still generated in the zebrafish pallium in the adult ${ }^{77,78}$. Thus, a small area of ventricular zone should be still present next to Dm to generate neurons for Dp. However, we have not observed neuroblasts migrating laterally across the pallium to reach $\mathrm{Dp}$ in the adult by BrdU pulse chase studies or genetic lineage tracing ${ }^{51,76,77}$. The "eversion-rearrangement theory" by Northcutt and Braford suggests that differential expansion of the ventricular surface of some pallial zones and differential proliferation and migration of neuroblasts from the different ventricular zones might result in displacement or shifting of the different pallial subdivisions ${ }^{33,64,75}$. Similar to the "partial pallial eversion model", they propose that a small stretch of Dp is still located between Dm and Dl. Our gene expression data does not support this aspect of both models, as we do not identify a small area of ventricular zone and neuronal layer sandwiched between Dm and Dc rostrally and Dm and Dld more caudally that matches the gene expression profile found in Dp.

In the "new eversion model", the eversion was suggested to occur in a caudolateral direction leading to a shift of the arrangement of the different pallial subdivisions ${ }^{37}$. Yamamoto and colleagues propose that ventral pallial and lateral pallial homologs are not present in the rostral but only in the caudal pallium. In their model they suggest that $\mathrm{Dp}$ is homologous to the lateral pallium ${ }^{37}$. In contrast, we find the putative ventral or ventral/lateral pallial homolog Dm contiguously from rostral to caudal. However, we also identify a separate Dp nucleus only in the posterior part of the pallium.

In contrast to the models discussed above, Nieuwenhuys has put forward that the lateral olfactory tract in vertebrates with everted telencephala is not homologous to the olfactory tract in vertebrates with evaginated telencephala ${ }^{4}$. He bases this on data that showed considerable variation in the pattern of secondary olfactory projections among different groups of ray-finned fishes and showed secondary olfactory projections both to Dm and $\mathrm{Dp}^{4,29,75}$. He suggests that the olfactory input has increased overall in Dl, with a subsequent confinement to Dp and has decreased in Dm during ray-fin fish evolution. He considers the lateral olfactory tract as an apomorphy of actinopterygian pallia ${ }^{4}$. Even though our gene expression data does not support the models that suggest a migration or displacement of $\mathrm{Dp}$ from a position equivalent to the lateral pallium to its caudolateral position, we can identify Dp as a subdivision of Dl separate from Dld. Furthermore, Neuropeptide Y and Parvalbumin immunohistochemistry clearly distinguishes Dl from $\mathrm{Dp}^{79}$. Furthermore, as discussed above, our gene expression data suggest that Dm might be homologous to the lateral pallium or comprise a combined ventral and lateral pallium, which might suggest that $\mathrm{Dp}$ is not homologous to the lateral pallium. Our gene expression data is consistent with Nieuwenhuys' model that Dp comprises a specialized part of Dl that receives olfactory input, even though the other parts of $\mathrm{Dl}$ might be homologous to the medial pallium and hippocampus in tetrapods (Figure 5A-D).

\section{Central part of the area dorsalis telencephali (Dc)}

In the "modified partial pallial eversion model" 32 , based on expression of Parvalbumin and nicotine adenine dinucleotide phosphate diphorase (NADPHd) in Dl, it was suggested that Dc is a true histogenetic unit that has its own germinative zone rostrally, but is caudally displaced to a more central location by differential growth of Dm and Dl. Mueller and colleagues suggest that Dc is homologous to the dorsal pallium in other vertebrates and that Dd is absent in zebrafish ${ }^{32}$. This model is consistent with connectional and gene expression data in Apteronotus leptorhynchus ${ }^{24}$. In addition, it has been noted that Dc shows no significant immunoreactivity to Calretinin, Neuropeptide Y or Thyrosine hydroxylase separating it from the surrounding areas of the pallium ${ }^{79}$. Other models based mainly on topology suggest that Dm, Dd and Dld are homologous to the dorsal pallium ${ }^{37}$, whereas others have homologized Dd with the dorsal pallium ${ }^{4,29,30,33,64}$ and have suggested that Dc is not a separate unit, but represents the deeper zone of the periventricular areas of Dm, Dd and Dl. Our gene expression data is consistent with the second part of the "modified pallial eversion model" of Mueller and colleagues. We have adapted the nomenclature of Mueller et al. (2011) to call the displaced nucleus Dc, even though our data do not rule out the possibility that Dc is rather a displaced Dd nucleus. Accordingly, Dc does not have its own germinative zone caudally, but only in the rostral part of the pallium. However, the morphogenesis of the telencephalon has been analyzed between $1 \mathrm{dpf}$ and $5 \mathrm{dpf}$ and no such displacement of Dc has been described ${ }^{5}$, so if it is the case, then it has to happen after $5 \mathrm{dpf}$. To conclusively evaluate the displacement of Dc, detailed lineage analysis using Cre/loxP technology should be performed from embryonic stages till adulthood.

\section{Gene expression in pallial progenitors}

In the adult zebrafish, proliferating cells are found scattered in the ventricular zone of the pallium ${ }^{76-78}$. In the adult zebrafish pallium, asclla is found in scattered cells in the ventricular zone of $\mathrm{Dm}$ and in Dlv/Dp. In addition, eomesa is present in scattered cells in the ventricular zone of Dm and in the ventricular zone of Dld and Dlv/Dp. Emxl is also present in the ventricular zone of Dp and emx3 is found in the ventricular zone of Dm, Dlv and Dp (Figure 5A-D).

In mouse, Ascll is expressed in a subpopulation of progenitors in the dorsal telencephalon ${ }^{61,62}$. Eomes (Tbr2) is present in intermediate progenitors in the cortex in the embryo and in the dentate gyrus both in the embryo and the adult and is part of the glutamatergic differentiation cascade that also contains NeuroD and Tbrl ${ }^{80}$. In the adult zebrafish, neurod and $t b r l$ as well as the vesicular glutamate transporters vglut1/2.1/2.2 marking glutamatergic neurons 
are expressed throughout the pallium, suggesting that the glutamatergic differentiation cascade may still be present in the adult zebrafish telencephalon ${ }^{7,72}$. The expression in scattered cells in the ventricular zone suggests that eomesa and asclla may label progenitor subpopulations in the pallium and eomesa could play a role in differentiation of glutamatergic neurons in the adult zebrafish brain. In addition, emx 1 and $e m x 3$ might be involved in regulating neuronal differentiation processes in the pallium. It will be interesting to perform comprehensive lineage analysis using Cre/loxP technology to follow the progeny of these different markers in the adult zebrafish.

\section{Conclusions}

In this study, we present a new model of the subdivisions in the adult zebrafish pallium based on conserved marker gene expression and propose putative homologies to pallial nuclei in tetrapods. Additional marker analysis, lineage tracing experiments and functional analyses are necessary to substantiate the proposed pallial subdivisions and their homology to pallial nuclei in tetrapods. It is important to identify pallial areas in adult zebrafish and their homologies to pallial nuclei in tetrapods to improve our knowledge about the zebrafish brain, in order to implement the zebrafish system as an ideal model for neurobiological research and as a model for human neurodegenerative diseases.

$\begin{array}{ll}\text { List of abbreviations } \\ \text { BNSM } & \text { bed nucleus of the stria medullaris } \\ \text { BST } & \text { bed nucleus of the stria terminalis } \\ \text { Cant } & \text { anterior commissure } \\ \text { D } & \text { area dorsalis telencephali } \\ \text { Dc } & \text { central part of the area dorsalis telencephali } \\ \text { Dd } & \text { dorsal part of the area dorsalis telencephali } \\ \text { D1 } & \text { lateral part of the area dorsalis telencephali } \\ \text { Dld } & \text { dorsal part of Dl } \\ \text { Dlv } & \text { ventral part of Dl } \\ \text { Dm } & \text { medial part of the area dorsalis telencephali } \\ \text { Dp } & \text { posterior part of the area dorsalis telencephali } \\ \text { dpf } & \text { days post fertilization } \\ \text { EN } & \text { entopeduncular nucleus } \\ \text { nl } & \text { neuronal layer }\end{array}$

\author{
OB olfactory bulb \\ Po preoptic region \\ $\mathrm{V} \quad$ area ventralis telencephali \\ $\mathrm{Vp} \quad$ postcommissural nucleus of the area ventralis telencephali \\ Vs supracommisural nucleus of the area ventralis telencephali \\ vz ventricular zone
}

\section{Data availability}

Figshare: Gene expression analysis in the adult zebrafish pallium. Doi: http://dx.doi.org/10.6084/m9.figshare.1266194 ${ }^{81}$

\section{Author contributions}

JG and MB conceived of the study and the experimental design, analyzed the data and co-wrote the manuscript. JG carried out most of the experiments, MB coordinated and supervised the study. VK performed the Prox1 immunohistochemistry. DF performed the asclla in situ hybridization. AM and MG performed the in situ hybridizations on larval brains. IB performed phylogenetic and synteny analyses. JK participated in the design of the study and helped analyze the data. All authors read and approved the final manuscript.

\section{Competing interests}

No competing interests were disclosed.

\section{Grant information}

This work was supported by grants to MB from the Deutsche Forschungsgemeinschaft (SFB 655 A3), European Union (ZF-Health) and the Center for Regenerative Therapies Dresden (CRTD).

The funders had no role in study design, data collection and analysis, decision to publish, or preparation of the manuscript.

\section{Acknowledgements}

We thank the Didier Stainier lab, the Monte Westerfield lab and the Steve Wilson lab for sharing plasmids. We are thankful to Anja Menge, Sabine Hübner, Julia Ludwig and Paul Morath for technical support. We thank Salvador Martinez and Stefano Suzzi for comments on the manuscript. 


\section{Supplementary figures}
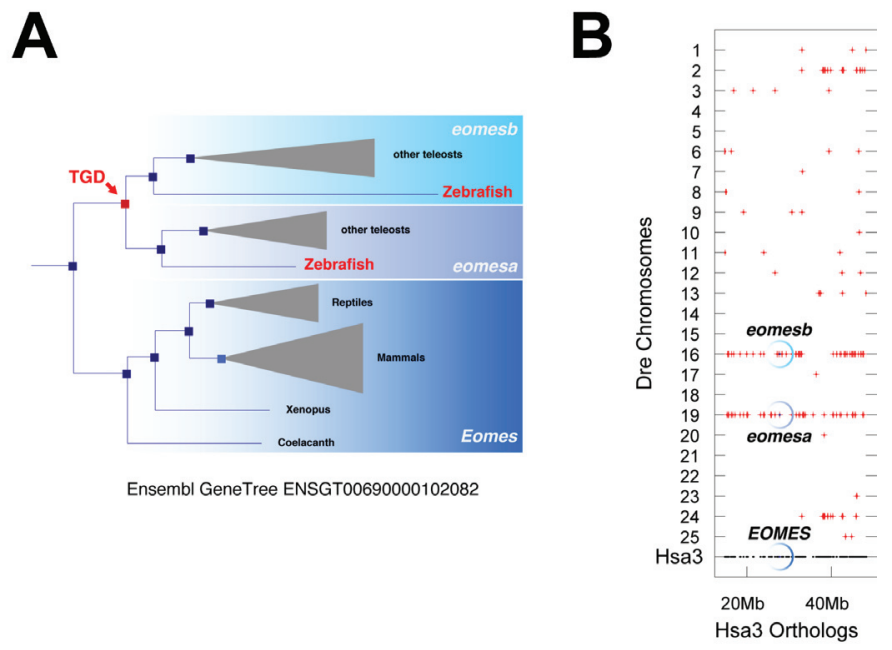

Figure S1. Teleost eomes genes. A. The topology of the Ensembl Gene Tree suggest that the teleost eomes co-orthologs, eomesa and eomesb, were duplicated at the base of the teleost lineage and thus most likely during the teleost genome duplication (TGD). B. Dotplot from the Synteny Database shows that the human EOMES gene region on chromosome Hsa3 shows extensive double conserved synteny to zebrafish chromosomes Dre19 and Dre16 which contain eomesa and eomesb, respectively, providing strong evidence for the TGD origin of teleost eomes co-orthologs.

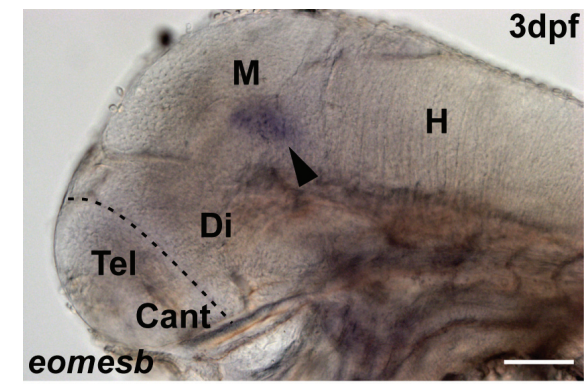

Figure S2. Expression of eomesb in the embryonic zebrafish brain. A. eomesb expression is not found in the telencephalon ( $T$ ), but present in the midbrain (M), arrowhead, shown is a lateral view. Di Diencephalon, H Hindbrain.

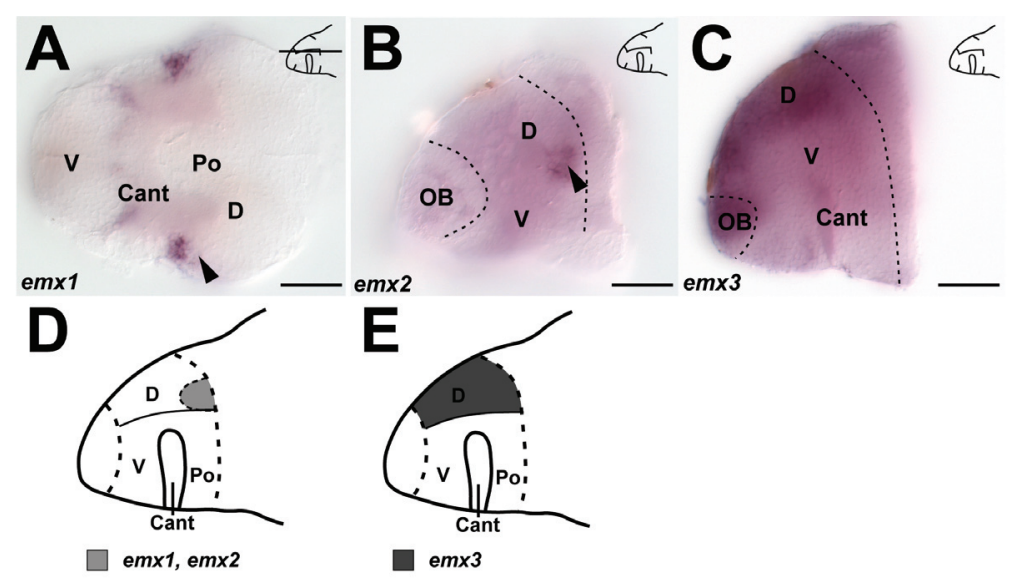

Figure S3. Expression of $\mathbf{e m \times 1}$, emx2 and emx3 in the zebrafish larval brain. A. emx1 expression is present in the lateral part of the dorsal telencephalon (D, arrowhead), shown is a ventral view. $\mathbf{B}$. emx2 expression is present in the lateral part of $D$ (arrowhead), shown is a parasaggital view. C. emx3 expression is present throughout $\mathbf{D}$, shown is a parasaggital view. $\mathbf{D}$. Summary of the distribution of emx1 and emx2 expression in $\mathbf{D}$ in a sagittal view. E. Summary of the distribution of emx3 expression in $\mathbf{D}$ in a sagittal view. A.-C. Brightfield wholemount images, A. ventral, B. - C. sagittal views. Scale bars $=50 \mu \mathrm{m} \mathbf{A}-\mathbf{C}$. 
1. Northcutt RG: The forebrain of gnathostomes: in search of a morphotype. Brain Behav Evol. 1995; 46(4-5): 275-318.

PubMed Abstract | Publisher Full Text

2. Northcutt RG: Evolution of the telencephalon in nonmammals. Annu Rev Neurosci. 1981; 4: 301-350.

PubMed Abstract | Publisher Full Text

3. Nieuwenhuys R, Meek J: The Telencephalon of Actinopterygian Fishes. Cereb Cortex. 1990; 8A: 31-73.

Publisher Full Text

4. Nieuwenhuys R: The forebrain of actinopterygians revisited. Brain Behav Evol. 2009; 73(4): 229-252.

PubMed Abstract | Publisher Full Text

5. Folgueira M, Bayley $\mathrm{P}$, Navratilova $\mathrm{P}$, et al:: Morphogenesis underlying the development of the everted teleost telencephalon. Neural Dev. 2012; 7: 32. PubMed Abstract | Publisher Full Text | Free Full Text

6. Butler $A B$, Hodos W: Comparative vertebrate neuroanatomy: evolution and adaptation. 2nd edn. Hoboken, N.J.: Wiley-Interscience; 2005. Publisher Full Text

7. Ganz J, Kaslin J, Freudenreich D, et al:: Subdivisions of the adult zebrafish subpallium by molecular marker analysis. J Comp Neurol. 2012; 520(3): 633-655.

PubMed Abstract | Publisher Full Text

8. Medina L, Brox A, Legaz I, et al.: Expression patterns of developmental regulatory genes show comparable divisions in the telencephalon of Xenopus and mouse: insights into the evolution of the forebrain. Brain Res Bull. 2005; 66(4-6): 297-302.

PubMed Abstract | Publisher Full Text

9. Brox A, Puelles L, Ferreiro B, et al.: Expression of the genes Emx1, Tbr1, and Eomes (Tbr2) in the telencephalon of Xenopus laevis confirms the existence of a ventral pallial division in all tetrapods. J Comp Neurol. 2004; 474(4): 562-577.

PubMed Abstract | Publisher Full Text

10. Puelles L, Kuwana E, Puelles E, et al:: Pallial and subpallial derivatives in the embryonic chick and mouse telencephalon, traced by the expression of the genes Dlx-2, Emx-1, Nkx-2.1, Pax-6, and Tbr-1. J Comp Neurol. 2000; 424(3): 409-438. PubMed Abstract

11. Flames N, Pla R, Gelman DM, et al.: Delineation of multiple subpallial progenitor domains by the combinatorial expression of transcriptional codes. $J$ Neurosci. 2007; 27(36): 9682-9695.

PubMed Abstract | Publisher Full Text

12. Puelles L, Kuwana E, Puelles E, et al.: Comparison of the mammalian and avian telencephalon from the perspective of gene expression data. Eur J Morphol. 1999; 37(2-3): 139-150.

PubMed Abstract | Publisher Full Text

13. Medina L, Legaz I, Gonzalez G, et al.: Expression of Dbx1, Neurogenin 2, Semaphorin 5A, Cadherin 8, and Emx1 distinguish ventral and lateral pallial histogenetic divisions in the developing mouse claustroamygdaloid complex. $J$ Comp Neurol. 2004; 474(4): 504-523.

PubMed Abstract | Publisher Full Text

14. Medina L, Abellan A: Development and evolution of the pallium. Semin Cell Dev Biol. 2009; 20(6): 698-711.

PubMed Abstract | Publisher Full Text

15. Abellan A, Vernier B, Retaux S, et al.: Similarities and differences in the forebrain expression of Lhx 1 and Lhx 5 between chicken and mouse: Insights for understanding telencephalic development and evolution. J Comp Neurol. 2010; 518(17): 3512-3528.

PubMed Abstract | Publisher Full Text

16. Abellan A, Legaz I, Vernier B, et al.: Olfactory and amygdalar structures of the chicken ventral pallium based on the combinatorial expression patterns of LIM and other developmental regulatory genes. J Comp Neurol. 2009; 516(3): 166-186.

PubMed Abstract | Publisher Full Text

17. Moreno N, Morona R, Lopez JM, et al.: Subdivisions of the turtle Pseudemys scripta subpallium based on the expression of regulatory genes and neurona markers. J Comp Neurol. 2010; 518(24): 4877-4902.

PubMed Abstract | Publisher Full Text

18. Moreno N, Gonzalez A, Retaux S: Evidences for tangential migrations in Xenopus telencephalon: developmental patterns and cell tracking experiments. Dev Neurobiol. 2008; 68(4): 504-520.

PubMed Abstract | Publisher Full Text

19. Moreno N, Dominguez L, Retaux S, et al.: Islet1 as a marker of subdivisions and cell types in the developing forebrain of Xenopus. Neuroscience. 2008; 154(4): 1423-1439.

PubMed Abstract | Publisher Full Text

20. Moreno N, Bachy I, Retaux S, et al.: LIM-homeodomain genes as developmenta and adult genetic markers of Xenopus forebrain functional subdivisions. J Comp Neurol. 2004; 472(1): 52-72. PubMed Abstract | Publisher Full Text

21. Bachy I, Berthon J, Retaux S: Defining pallial and subpallial divisions in the developing Xenopus forebrain. Mech Dev. 2002; 117(1-2): 163-172. PubMed Abstract | Publisher Full Text
22. Gonzalez A, Morona R, Moreno N, et al.: Identification of striatal and pallidal regions in the subpallium of anamniotes. Brain Behav Evol. 2014; 83(2): 93-103. PubMed Abstract

23. Bulfone A, Martinez S, Marigo V, et al:: Expression pattern of the Tbr2 (Eomesodermin) gene during mouse and chick brain development. Mech Dev. 1999; 84(1-2): 133-138.

PubMed Abstract | Publisher Full Text

24. Harvey-Girard E, Giassi AC, Ellis W, et al.: Organization of the gymnotiform fish pallium in relation to learning and memory: IV. Expression of conserved transcription factors and implications for the evolution of dorsal telencephalon. J Comp Neurol. 2012; 520(15): 3395-3413. PubMed Abstract | Publisher Full Text

25. Giassi AC, Harvey-Girard E, Valsamis B, et al:: Organization of the gymnotiform fish pallium in relation to learning and memory: I. Cytoarchitectonics and cellular morphology. J Comp Neurol. 2012; 520(12): 3314-3337. PubMed Abstract | Publisher Full Text

26. Giassi AC, Ellis W, Maler L: Organization of the gymnotiform fish pallium in relation to learning and memory: III. Intrinsic connections. J Comp Neurol. 2012; 520(15): 3369-3394.

PubMed Abstract | Publisher Full Text

27. Giassi AC, Duarte TT, Ellis W, et al:: Organization of the gymnotiform fish pallium in relation to learning and memory: II. Extrinsic connections. J Comp Neurol. 2012; 520(15): 3338-3368.

PubMed Abstract | Publisher Full Text

28. Burmeister SS, Munshi RG, Fernald RD: Cytoarchitecture of a cichlid fish telencephalon. Brain Behav Evol. 2009; 74(2): 110-120. PubMed Abstract | Publisher Full Text | Free Full Text

29. Northcutt RG: Connections of the lateral and medial divisions of the goldfish telencephalic pallium. J Comp Neurol. 2006; 494(6): 903-943.

PubMed Abstract | Publisher Full Text

30. Northcutt RG: Forebrain evolution in bony fishes. Brain Res Bull. 2008; 75(2-4) 191-205.

PubMed Abstract | Publisher Full Text

31. Wullimann MF, Mueller T: Teleostean and mammalian forebrains contrasted: Evidence from genes to behavior. J Comp Neurol. 2004; 475(2): 143-162. PubMed Abstract | Publisher Full Text

32. Mueller T, Dong Z, Berberoglu MA, et al.: The dorsal pallium in zebrafish, Danio rerio (Cyprinidae, Teleostei). Brain Res. 2011; 1381: 95-105. PubMed Abstract | Publisher Full Text | Free Full Text

33. Braford MR Jr: Comparative aspects of forebrain organization in the ray-finned fishes: touchstones or not? Brain Behav Evol. 1995; 46(4-5): 259-274. PubMed Abstract | Publisher Full Text

34. Kaslin J, Panula P: Comparative anatomy of the histaminergic and other aminergic systems in zebrafish (Danio rerio). J Comp Neurol. 2001; 440(4): 342-377.

PubMed Abstract | Publisher Full Text

35. Kaslin J: The aminergic and cholinergic neurotransmitter systems in the zebrafish brain. Abo Akademi University, Department of Biology; 2004. Reference Source

36. Folgueira M, Anadon R, Yanez J: Experimental study of the connections of the telencephalon in the rainbow trout (Oncorhynchus mykiss). II: Dorsal area and preoptic region. J Comp Neurol. 2004; 480(2): 204-233. PubMed Abstract | Publisher Full Text

37. Yamamoto N, Ishikawa $\mathrm{Y}$, Yoshimoto $\mathrm{M}$, et al.: A new interpretation on the homology of the teleostean telencephalon based on hodology and a new eversion model. Brain Behav Evol. 2007; 69(2): 96-104. PubMed Abstract | Publisher Full Text

38. O'Connell LA, Hofmann HA: The vertebrate mesolimbic reward system and social behavior network: a comparative synthesis. J Comp Neurol. 2011; 519(18): 3599-3639.

PubMed Abstract | Publisher Full Text

39. Broglio C, Rodriguez F, Gomez A, et al:: Selective involvement of the goldfish lateral pallium in spatial memory. Behav Brain Res. 2010; 210(2): 191-201. PubMed Abstract | Publisher Full Text

40. Broglio C, Gomez A, Duran E, et al.: Hallmarks of a common forebrain vertebrate plan: specialized pallial areas for spatial, temporal and emotional memory in actinopterygian fish. Brain Res Bull. 2005; 66(4-6): 277-281. PubMed Abstract | Publisher Full Text

41. Rodriguez F, Lopez JC, Vargas JP, et al:: Conservation of spatial memory function in the pallial forebrain of reptiles and ray-finned fishes. $J$ Neurosci. 2002; 22(7): 2894-2903. PubMed Abstract

42. Rodriguez F, Lopez JC, Vargas JP, et al.: Spatial memory and hippocampal pallium through vertebrate evolution: insights from reptiles and teleost fish. Brain Res Bull. 2002; 57(3-4): 499-503. PubMed Abstract | Publisher Full Text

43. Duran E, Ocana FM, Broglio C, et al:: Lateral but not medial telencephalic pallium ablation impairs the use of goldfish spatial allocentric strategies in a "hole-board" task. Behav Brain Res. 2010; 214(2): 480-487.

PubMed Abstract | Publisher Full Text

44. Brand M, Granato M, Nuesslein-Volhard C: Keeping and raising zebrafish. In 
Zebrafish: A Practical Approach. Edited by Nuesslein-Volhard C, Dahm, R. Oxford: Oxford University Press; 1999.

Reference Source

45. Westerfield M: The zebrafish book. A guide for the laboratory use of zebrafish (Danio rerio). 4 edn. Eugene: University of Oregon Press; 1995 Reference Source

46. Streisinger G, Walker C, Dower N, et al:: Production of clones of homozygous diploid zebra fish (Brachydanio rerio). Nature. 1981; 291(5813): 293-296. PubMed Abstract | Publisher Full Text

47. Braasch I, Postlethwait J: Polyploidy in Fish and the Teleost Genome Duplication. In Polyploidy and Genome Evolution. Edited by Soltis PS, Soltis DE: Springer Berlin Heidelberg; 2012: 341-383. Publisher Full Text

48. Catchen JM, Conery JS, Postlethwait JH: Automated identification of conserved synteny after whole-genome duplication. Genome Res. 2009; 19(8): 1497-1505. PubMed Abstract | Publisher Full Text | Free Full Text

49. Viktorin G, Chiuchitu C, Rissler M, et al.: Emx3 is required for the differentiation of dorsal telencephalic neurons. Dev Dyn. 2009; 238(8): 1984-1998. PubMed Abstract | Publisher Full Text | Free Full Text

50. Reifers $\mathrm{F}$, Bohli $\mathrm{H}$, Walsh EC, et al:: Fgf8 is mutated in zebrafish acerebellar (ace) mutants and is required for maintenance of midbrain-hindbrain boundary development and somitogenesis. Development. 1998; 125(13): 2381-2395. PubMed Abstract

51. Kroehne V, Freudenreich D, Hans S, et al.: Regeneration of the adult zebrafish brain from neurogenic radial glia-type progenitors. Development. 2011; 138(22): $4831-4841$

PubMed Abstract | Publisher Full Text

52. Mueller T, Wullimann MF, Guo S: Early teleostean basal ganglia development visualized by zebrafish DIx2a, Lhx6, Lhx7, Tbr2 (eomesa), and GAD67 gene expression. J Comp Neurol. 2008; 507(2): 1245-1257. PubMed Abstract | Publisher Full Text

53. Mione M, Shanmugalingam S, Kimelman D, et al: Overlapping expression of zebrafish T-brain-1 and eomesodermin during forebrain development. Mech Dev. 2001; 100(1): 93-97. PubMed Abstract | Publisher Full Text

54. Costagli A, Kapsimali M, Wilson SW, et al: Conserved and divergent patterns of Reelin expression in the zebrafish central nervous system. $J$ Comp Neurol. 2002; 450(1): 73-93.

PubMed Abstract | Publisher Full Text

55. Kawahara A, Dawid IB: Developmental expression of zebrafish emx1 during early embryogenesis. Gene Expr Patterns. 2002; 2(3-4): 201-206. PubMed Abstract | Publisher Full Text

56. Morita $\mathrm{T}$, Nitta $\mathrm{H}$, Kiyama $\mathrm{Y}$, et al.: Differential expression of two zebrafish emx homeoprotein mRNAs in the developing brain. Neurosci Lett. 1995; 198(2): 131-134.

PubMed Abstract | Publisher Full Text

57. Lavado A, Oliver G: Prox1 expression patterns in the developing and adult murine brain. Dev Dyn. 2007; 236(2): 518-524.

PubMed Abstract | Publisher Full Text

58. Lavado A, Lagutin OV, Chow LM, et al.: Prox1 is required for granule cell maturation and intermediate progenitor maintenance during brain neurogenesis. PLOS Biol. 2010; 8(8): pii: e1000460 PubMed Abstract | Publisher Full Text | Free Full Text

59. Galeeva A, Treuter E, Tomarev S, et al:: A prospero-related homeobox gene Prox-1 is expressed during postnatal brain development as well as in the adult rodent brain. Neuroscience. 2007; 146(2): 604-616. PubMed Abstract | Publisher Full Text

60. Iwano $\mathrm{T}$, Masuda $\mathrm{A}$, Kiyonari $\mathrm{H}$, et al: Prox1 postmitotically defines dentate gyrus cells by specifying granule cell identity over CA3 pyramidal cell fate in the hippocampus. Development. 2012; 139(16): 3051-3062. PubMed Abstract | Publisher Full Text

61. Britz $\mathrm{O}$, Mattar $\mathrm{P}$, Nguyen $\mathrm{L}$, et al:: A role for proneural genes in the maturation of cortical progenitor cells. Cereb Cortex. 2006; 16(Suppl 1): i138-151. PubMed Abstract | Publisher Full Text

62. Fode $\mathrm{C}, \mathrm{Ma} \mathrm{Q}$, Casarosa $\mathrm{S}$, et al:: A role for neural determination genes in specifying the dorsoventral identity of telencephalic neurons. Genes Dev. 2000; 14(1): 67-80.

PubMed Abstract | Free Full Text

63. Wullimann MF, Mueller T: Expression of Zash-1a in the postembryonic zebrafish brain allows comparison to mouse Mash1 domains. Brain Res Gene Expr
Patterns. 2002; 1(3-4): 187-192.

PubMed Abstract | Publisher Full Text

64. Braford MR Jr: Stalking the everted telencephalon: comparisons of forebrain organization in basal ray-finned fishes and teleosts. Brain Behav Evol. 2009; 74(1): 56-76.

PubMed Abstract | Publisher Full Text

65. Portavella M, Vargas JP, Torres B, et al:: The effects of telencephalic pallia lesions on spatial, temporal, and emotional learning in goldfish. Brain Res Bull. 2002; 57(3-4): 397-399.

PubMed Abstract | Publisher Full Tex

66. Portavella M, Torres B, Salas C, et al.: Lesions of the medial pallium, but not of the lateral pallium, disrupt spaced-trial avoidance learning in goldfish (Carassius auratus). Neurosci Lett. 2004; 362(2): 75-78.

PubMed Abstract | Publisher Full Text

67. Moreno N, Gonzalez A: Evolution of the amygdaloid complex in vertebrates, with special reference to the anamnio-amniotic transition. J Anat. 2007; 211(2): 151-163.

PubMed Abstract | Publisher Full Text | Free Full Text

68. Maximino C, Lima MG, Oliveira KR, et al:: "Limbic associative" and "autonomic" amygdala in teleosts: a review of the evidence. J Chem Neuroanat. 2013; 48-49: $1-13$.

PubMed Abstract | Publisher Full Text

69. Mailleux $\mathrm{P}$, Vanderhaeghen $\mathrm{JJ}$ : Distribution of neuronal cannabinoid receptor in the adult rat brain: a comparative receptor binding radioautography and in situ hybridization histochemistry. Neuroscience. 1992; 48(3): 655-668. PubMed Abstract | Publisher Full Text

70. Matsuda LA, Bonner TI, Lolait SJ: Localization of cannabinoid receptor mRNA in rat brain. J Comp Neurol. 1993; 327(4): 535-550.

PubMed Abstract | Publisher Full Text

71. Lam CS, Rastegar S, Strahle U: Distribution of cannabinoid receptor 1 in the CNS of zebrafish. Neuroscience. 2006; 138(1): 83-95.

PubMed Abstract | Publisher Full Text

72. Aoki T, Kinoshita M, Aoki R, et al:: Imaging of neural ensemble for the retrieval of a learned behavioral program. Neuron. 2013; 78(5): 881-894. PubMed Abstract | Publisher Full Text

73. Harvey-Girard E, Giassi AC, Ellis W, et al:: Expression of the cannabinoid CB1 receptor in the gymnotiform fish brain and its implications for the organization of the teleost pallium. J Comp Neurol. 2013; 521(4): 949-75. PubMed Abstract | Publisher Full Text

74. Mueller T, Wullimann MF: An evolutionary interpretation of teleostean forebrain anatomy. Brain Behav Evol. 2009; 74(1): 30-42. PubMed Abstract | Publisher Full Text

75. Northcutt R, Braford MR Jr: New observations on the organization and evolution of the telencephalon of the actinopterygian fishes. In Comparative Neurology of the Telencephalon Edited by SOE E. New York: Plenum Press; 1980: 41-98. Publisher Full Text

76. Ganz J, Kaslin J, Hochmann S, et al.: Heterogeneity and Fgf dependence of adult neural progenitors in the zebrafish telencephalon. Glia. 2010; 58(11): 1345-1363.

PubMed Abstract | Publisher Full Text

77. Grandel H, Kaslin J, Ganz J, et al.: Neural stem cells and neurogenesis in the adult zebrafish brain: origin, proliferation dynamics, migration and cell fate. Dev Biol. 2006; 295(1): 263-277.

PubMed Abstract | Publisher Full Text

78. Adolf $\mathrm{B}$, Chapouton $\mathrm{P}, \mathrm{Lam} \mathrm{CS}$, et al.: Conserved and acquired features of adult neurogenesis in the zebrafish telencephalon. Dev Biol. 2006; 295(1): 278-293.

PubMed Abstract | Publisher Full Text

79. Castro A, Becerra M, Manso MJ, et al:: Calretinin immunoreactivity in the brain of the zebrafish, Danio rerio: distribution and comparison with some neuropeptides and neurotransmitter-synthesizing enzymes. II. Midbrain, hindbrain, and rostral spinal cord. J Comp Neurol. 2006; 494(5): 792-814. PubMed Abstract | Publisher Full Text

80. Hevner RF, Hodge RD, Daza RA, et al:: Transcription factors in glutamatergic neurogenesis: conserved programs in neocortex, cerebellum, and adult hippocampus. Neurosci Res. 2006; 55(3): 223-233. PubMed Abstract | Publisher Full Text

81. Ganz J, Kroehne V, Freundenreich D, et al:: Gene expression analysis in the adult zebrafish pallium. Figshare. 2014. Data Source 


\section{Open Peer Review}

\section{Current Peer Review Status:}

\section{Version 1}

Reviewer Report 20 February 2015

https://doi.org/10.5256/f1000research.5978.r7077

(C) 2015 Wilson S. This is an open access peer review report distributed under the terms of the Creative Commons Attribution License, which permits unrestricted use, distribution, and reproduction in any medium, provided the original work is properly cited.

\section{Stephen W. Wilson}

Department of Cell and Developmental Biology, University College London, London, UK

In teleosts, the pallial telencephalon undergoes eversion during its development rather than the more common evagination that occurs in other vertebrates. These differing modes of morphogenesis have made it difficult to resolve homologies between pallial domains in teleosts and other vertebrates. This paper describes the pallial expression of zebrafish orthologues of genes that have helped to define pallial sub-domains in other vertebrates. The methods are clearly described, the data are of high quality and the discussion of results are balanced and informative. The authors acknowledge the limitations of using gene expression patterns and suggest additional experimental approaches that could be used to address the validity of hypotheses raised in the discussion of the data. There is a great deal of information of use for comparative neuroanatomy studies and some observations challenge current models of teleost telencephalic organisation. The expression analyses suggest that pallial sub-divisions show considerable variation from rostral to caudal telencephalon and it will be interesting to study how such organisation arises during development. I have no revisions that I consider to be essential. I think that Monica Flogueira's concern about the summary figure potentially being misleading could most simply be addressed by adding a question mark after the suggested homology term.

Competing Interests: No competing interests were disclosed.

\section{I confirm that I have read this submission and believe that I have an appropriate level of expertise to confirm that it is of an acceptable scientific standard.}

Reviewer Report 29 January 2015

https://doi.org/10.5256/f1000research.5978.r7076

(C) 2015 Panula P. This is an open access peer review report distributed under the terms of the Creative Commons Attribution License, which permits unrestricted use, distribution, and reproduction in any medium, provided the original work is properly cited. 


\section{Perrti Panula}

Institute of Biomedicine, University of Helsinki, Helsinki, Finland

The title accurately describes the contents of the paper, and the abstract describes the findings and main conclusions well.The analysis of the selected markers in adult zebrafish telencephalon, particularly the pallium as is done here, is important for any functional studies on the zf brain. The study thus forms a good basis for further studies on adult fish brain. I have some comments on the controls below. Whereas the adult part is of high quality and will be very helpful in further analysis of e.g. circuits (which are essential to understand the functional significance of the results) and behavior, the developmental part could be improved.

Some detailed comments:

1. It needs to be indicated how the probe specificity has been verified. No probe-controls cannot replace a non-reacting probe control such as sense probe or partly scrambled probe controls, because occasionally probes bind non-specifically to e.g. proteins.

2. From the point of view of the conclusions regarding correlation to telencephalic areas of other species, the developmental part in the study could be improved. Although mentioned in the abstract, only a limited dataset is shown at $7 \mathrm{dpf}$ (on p. 4, last chapter), and even here the data is difficult to find because the title indicates only analysis of adults. The age/stage of the samples is not indicated in Fig. S3, and the samples look earlier than $7 \mathrm{dpf}$. It would be particularly useful to see a series a developmental series in a set of images in which the brain domains could be easily identified. In this respect Fig.S3 is of limited value. The resolution is not very good, and clearly better figures could be provided. At least from $5 \mathrm{dpf}$ on the brains are easily prepared from the skull and penetration is excellent. Adding data on the developmental expression series would significantly improve the paper. Whole brain ish can be easily done on even 1-month-old fish. The data during the whole first week, or (even better) two weeks would be useful.

In summary, the adult data is very useful and only a note on controls should be added. The developmental data could be improved to the same high level as the adult data.

Competing Interests: No competing interests were disclosed.

\section{I confirm that I have read this submission and believe that I have an appropriate level of expertise to confirm that it is of an acceptable scientific standard, however I have significant reservations, as outlined above.}

Reviewer Report 08 January 2015

https://doi.org/10.5256/f1000research.5978.r7078

(C) 2015 Folgueira $\mathbf{M}$. This is an open access peer review report distributed under the terms of the Creative Commons Attribution License, which permits unrestricted use, distribution, and reproduction in any medium, provided the original work is properly cited. 


\section{Monica Folgueira}

Department of Cellular and Molecular Biology, University of A Coruña, A Coruña, Spain

Morphological differences between evaginated and everted telencephali hampers comparisons between brain morphotypes and complicates establishing homologies. This manuscript presents a comparative analysis of the expression pattern of a few transcription factors in the everted pallium of the zebrafish. These data will help us understand the organization of the zebrafish pallium and compare it with the pallium of other vertebrates. The manuscript will be of interest for readers working on comparative neuroanatomy and development, among other fields.

The manuscript is generally clear, well written and appropriate. The analysis of data is generally well performed, but maybe authors could clarify the following points:

Based on their expression analysis, authors identify five subdivisions of the pallium that they name as Dm, Dlv, Dld, Dc and Dp after adapting nomenclature from Mueller et al. (2011). I think it could be clearer in the text how data supports the division between "Dc" and "Dld" at rostral levels. In addition, as authors show that "Dld" represents a different histogenic unit to "Dlv", I wonder if "Dld" could be equivalent to "Dd/Dld" of other teleosts. Maybe authors could comment on this in the manuscript.

eomesa and Prox1 seem to show differences between anterior and posterior regions of Dld. Yet, authors consider Dld as a continuous unit. Dc also seems to show differences from rostral to caudal levels (e.g. emx2+ is only expressed in a caudal portion of Dc, while eomesa is only expressed in a rostral portion). Thus I wonder if more subnuclei could be identified in the zebrafish pallium, thus the organization of the pallium being even more complex. Maybe authors could comment on these observations (if correct).

Authors discuss the divisions of the zebrafish pallium as corresponding to histogenic units of other vertebrates (ventral, lateral, dorsal and medial pallium). In addition, they propose certain homologies for specific nuclei, such as "Dm" being homologous to the "pallial amygdala" or "caudal part of Dld" homologous to the "dentate gyrus". In my opinion, it is right to propose and discuss about such putative homologies in the manuscript. However, in my opinion, they are too speculative to be included in a summary figure, as this could mislead readers. I suggest removing these homologies from diagrams A-D in Figure 5, just

\section{Minor comments:} referring to putative homologies for histogenic units.

Discussion: authors state that 'Our gene expression data is consistent with the second part of the "modified pallial eversion model" of Mueller and colleagues' To me, it is not clear what to authors mean by "second part of the modified pallial eversion model".

Figure 1C-D: ventricular expression is not clear in the original data sets.

Figure 2C: Authors state that red lines indicate subdivisions based on the current marker. However, emx2 only seems to be labelling a central area at this telenphalic level (Dc). So, it does not seem to support the limits between Dm, DI and Dp.

Figure S3: stages of development of the larvae are missing. Image C: in my opinion, OB limits are not accurately marked. Although the stage of development of the larva is not shown, the OB is certainly bigger than labelled between 3-5dpf (it seems correctly marked 
but not labelled in E-D).

I find the abbreviation TGD unnecessary.

Competing Interests: No competing interests were disclosed.

\section{I confirm that I have read this submission and believe that I have an appropriate level of expertise to confirm that it is of an acceptable scientific standard.}

Author Response 24 Oct 2015

Julia Ganz, Technische Universität Dresden, Dresden, Germany

We thank Monica Folgueira for her helpful comments and suggestions.

Based on their expression analysis, authors identify five subdivisions of the pallium that they name as Dm, Dlv, Dld, Dc and Dp after adapting nomenclature from Mueller et al. (2011). I think it could be clearer in the text how data supports the division between "Dc" and "Dld" at rostral levels.

The difference between Dc and DId is the absence of emx3 positive cells in Dld. We have included this point in the discussion to make it clearer and now write:

"Dld is different from Dc based on absence of emx3 positive cells in Dld."

In addition, as authors show that "Dld" represents a different histogenic unit to "Dlv", I wonder if "DId" could be equivalent to "Dd/DId" of other teleosts. Maybe authors could comment on this in the manuscript.

The unit "Dld" could be an equivalent to "Dd/DId" of other teleosts (such as in trout). As there are, however, to our knowledge, no good markers that have been used to identify "Dd/Dld", we do not want to introduce another subdivision that has not been used so far in zebrafish. It would be really interesting though to test if our proposed subdivision "DId" is equivalent to "Dd/Dld".

eomesa and Prox1 seem to show differences between anterior and posterior regions of Dld. Yet, authors consider Dld as a continuous unit. Dc also seems to show differences from rostral to caudal levels (e.g. em $x 2+$ is only expressed in a caudal portion of Dc, while eomesa is only expressed in a rostral portion). Thus I wonder if more subnuclei could be identified in the zebrafish pallium, thus the organization of the pallium being even more complex. Maybe authors could comment on these observations (if correct).

We have included different color coding in our summary figure to reflect these changes in gene expression (light green - medium green - dark green for Dc, and light yellow - dark yellow for Dld). We have also added an explanation to this color code in the figure legend and write:

"The different shades of green (Dc) and yellow (Dld) indicate gene expression changes along the rostro-caudal axis."

At this point, we have avoided adding additional subdivision acronyms as they might be potentially confusing especially when comparing the subdivisions in zebrafish to other teleost species.

Authors discuss the divisions of the zebrafish pallium as corresponding to histogenic 
units of other vertebrates (ventral, lateral, dorsal and medial pallium). In addition, they propose certain homologies for specific nuclei, such as "Dm" being homologous to the "pallial amygdala" or "caudal part of Dld" homologous to the "dentate gyrus". In my opinion, it is right to propose and discuss about such putative homologies in the manuscript. However, in my opinion, they are too speculative to be included in a summary figure, as this could mislead readers. I suggest removing these homologies from diagrams A-D in Figure 5, just referring to putative homologies for histogenic units.

We have adopted the suggestion from the reviewer Steve Wilson to add a question mark to figure 5 ("Putative homologous region in the tetrapod pallium (?)") to indicate that the putative homologies that we propose based on our work will need additional studies. We also point this out both in the figure legend of figure 5 and at the beginning of the discussion.

\section{Minor comments:}

Discussion: authors state that 'Our gene expression data is consistent with the second part of the "modified pallial eversion model" of Mueller and colleagues' To me, it is not clear what to authors mean by "second part of the modified pallial eversion model".

We have clarified the text and now write:

"Our gene expression data is consistent with the "modified partial pallial eversion model" of Mueller and colleagues with regard to Dc."

Figure 1C-D: ventricular expression is not clear in the original data sets.

The cells at caudal levels of the telencephalon are scattered and a bit weaker labeled than at rostral levels, but there are scattered eomesa positive cells present at the ventricular zone of Dm at all levels.

Figure 2C: Authors state that red lines indicate subdivisions based on the current marker. However, emx2 only seems to be labelling a central area at this telencephalic level (Dc). So, it does not seem to support the limits between Dm, DI and Dp.

We have modified this and changed the red lines in the figure.

Figure S3: stages of development of the larvae are missing. Image C: in my opinion, OB limits are not accurately marked. Although the stage of development of the larva is not shown, the OB is certainly bigger than labelled between 3-5dpf (it seems correctly marked but not labelled in E-D).

We have included the stages of development in the figure legend. We have included the OB label in S3E,D. We have changed the OB limits in the figure S3C accordingly.

I find the abbreviation TGD unnecessary.

The abbreviation has been removed.

Competing Interests: No competing interests were disclosed. 


\section{Comments on this article}

\section{Version 1}

\section{Reader Comment 30 Dec 2014}

Florencia Cavodeassi, Centro de Biología Molecular Severo Ochoa (CSIC-UAM), Spain

Telencephalic morphogenesis in teleosts is very different to that of tetrapods - while the telencephalon in tetrapods undergoes invagination, resulting in the formation of two telencephalic vesicles, telencephalon morphogenesis in teleosts occurs by eversion and results in the formation of an unpaired vesicle. This fact has greatly complicated our ability to establish neuroanatomical correlations between tetrapods and teleosts, an essential task to allow us exploiting the advantages of the zebrafish in neurobiology studies. The comparative analysis done here by the authors allows to establish putative homologies between teleosts' and tetrapods' pallial nuclei, setting down the basis for further functional studies. It thus constitutes a valuable source of information to help in the comparison of telencephalic organisation between teleosts and tetrapods.

Competing Interests: there are no competing interests

\section{Reader Comment 22 Dec 2014}

Steffen Scholpp, Institute for Toxicology and Genetics, Karlsruhe Institute of Technology (KIT), Germany

This manuscript provides a comprehensive analysis of the expression pattern of transcription factors such as members of the emx family, tbr2/eomesa and prox 1 in the adult pallium of teleost. This article contributes in a substantial way to our understanding of evolutionary concepts leading to telencephalic diversification. The lateral nucleus of the pallium in teleosts (DI) was suggested to have similar function like the hippocampus and the central part (Dc) has homology to the cortex in tetrapods. Based on the detailed expression analysis, the authors suggest that the dorsal part of the pallium (Dp) is a part of the $\mathrm{Dl} /$ hippocampus. Interestingly the authors show that this brain part harbors an olfactory input nucleus. It will be interesting to see if the Dp acts as functional interface between the DI/hippocampus and Dc/cortex similar to the entorhinal cortex, supported by its olfactory inputs or if this is a specialized evolved structure during ray-fin fish evolution as suggested by Nieuwenhuys. This detailled expression analysis will allow further functional studies to compare homolog nuclei in the pallium of vertebrate model organisms in the future.

Competing Interests: There are no competing interests.

Reader Comment 19 Dec 2014

Richard Dorsky, University of Utah Health Sciences Center, USA

This is a fantastic resource for the zebrafish neuroscience community, as well as others interested 
in comparative neuroanatomy. The molecular evidence provided will help clarify competing models of the relationships between pallial anatomy in teleosts and tetrapods. In addition, the gene expression patterns presented here will be useful as markers for specific cell populations, and as potential tools for genetic manipulation of neuronal subsets.

Competing Interests: no competing interests

The benefits of publishing with F1000Research:

- Your article is published within days, with no editorial bias

- You can publish traditional articles, null/negative results, case reports, data notes and more

- The peer review process is transparent and collaborative

- Your article is indexed in PubMed after passing peer review

- Dedicated customer support at every stage

For pre-submission enquiries, contact research@f1000.com 